\title{
Variação temporal do nível freático do aqüífero cárstico de Irecê - Bahia: contribuição para uso e gestão das águas subterrâneas no semi-árido
}

\author{
Sandro Oliveira Ramos ${ }^{1}$, Heráclio Alves de Araújo ${ }^{1}$, Luiz Rogério Bastos Leal', \\ Joana Angélica Guimarães da Luz \& Alan Robert Dutton ${ }^{4}$
}

\begin{abstract}
Resumo A micro-região de Irecê, área objeto desse estudo, localizada na região central do estado da Bahia à margem direita do rio São Francisco, abrange uma área total de $9.380 \mathrm{~km}^{2}$. Essa região é conhecida nacionalmente por sua potencialidade agrícola, com destaque para a cultura do feijão, cenoura, beterraba e cebola. Devido à grande disponibilidade de solos para as atividades agrícolas, têm-se observado um aumento desordenado de áreas irrigadas, utilizando águas subterrâneas do aqüífero cárstico da região. O aqüífero cárstico de Irecê é um aqüífero livre, cuja superfície piezométrica acompanha a topografia regional e tem o fluxo subterrâneo em direção às calhas dos rios da região. Medidas de nível freático do aqüífero e das precipitações regionais realizadas entre os anos 2002 e 2004 revelaram que o manejo inadequado das práticas de irrigação na região, em associação ao uso das águas para abastecimento humano e animal, tem provocado o contínuo rebaixamento do nível hidrostático do aqüífero durante os últimos 20 anos e indica que o mesmo está sendo utilizado em regime de subrexplotação e de forma não-sustentável.
\end{abstract}

Palavras-chave: aqüífero cárstico, recarga, gestão das águas subterrâneas, bacia de Irecê.

\begin{abstract}
Temporal Variation of the Water Table in the Karstic Aquifer of the Irecê Basin, Bahia: Contribution for Using and Managing Groundwater in Semi-Arid Areas. The micro-region of Irecê, object area of this study, situated in the central region of the state of Bahia on the right margin of the São Francisco river, encloses an area of $9,380 \mathrm{~km}^{2}$. This region is known nationally for its great agricultural potentiality, mainly the bean culture, and more recently, the carrot, beetroot and onion cultures. Because of the great land availability for agricultural activities, we have observed a disordered increase of the irrigated areas, making use of the region's underground water of the karst aquifer. During the last two decades, both population increase and agricultural activity have accelerated in Bahia's Irecê region. The combination of the productive agricultural land, abundant groundwater reserves, excellent groundwater quality, absence of governmental regulation, and low-cost flood irrigation systems explain the increases in the number of groundwater production wells and the amount of acreage under irrigation throughout Irecê region. Water levels in the aquifer are falling rapidly (average of $\sim 1 \mathrm{~m} / \mathrm{yr}$ ). Drawdown of the potentiometric surface in turn impacts the discharge of springs base flow of rivers. The potential for groundwater contamination from agricultural activities and waste-disposal practices is an increasing concern.
\end{abstract}

Keywords: karst aquifer, recharge, groundwater management, Irecê basin.

INTRODUÇÃO A micro-região de Irecê, localizada na região central do estado da Bahia, no domínio das bacias hidrográficas dos rios Verde e Jacaré, afluentes da margem direita do rio São Francisco, é conhecida como uma importante região agrícola do Nordeste brasileiro, com destaque para as culturas de feijão, cenoura, beterraba e cebola. Devido à ampla disponibilidade de solos férteis e água subterrânea houve um grande aumento das áreas irrigadas nos últimos 20 anos na região, passando de 900 Ha. no ano de 1993 para cerca de 5.900 Ha. em 2004 (Bastos Leal \& Silva 2004). Em função desse aumento de demanda por água na região, o número de poços tubulares perfurados na região passou de
1.000 poços no final da década 70 para cerca de 6.000 no ano 2004 , estando cerca de $70 \%$ desses poços atualmente em atividade (Bastos Leal \& Silva 2004). Como na maioria das áreas cársticas do mundo, na região de Irecê não há grandes mananciais de água superficial, de forma que a água subterrânea é a mais importante fonte de abastecimento para o uso agrícola e animal e complementar para o uso humano e industrial.

Além das atividades agropecuárias e rápido crescimento demográfico na região, a ocorrência de períodos secos prolongados, irregularidade e má distribuição espacial das precipitações, com média anual entre 500 e 600 $\mathrm{mm} / \mathrm{ano}$, tem ampliado a demanda por água subterrânea,

1 - Superintendência de Recursos Hídricos, Salvador (BA), Brasil. E-mail: sandro@srh.ba.gov.br, heraclio@srh.ba.gov.br

2 - Departamento de Geologia e Geofísica Aplicada, Instituto de Geociências da UFBA, Salvador (BA), Brasil. E-mail: lrogerio@ufba.br

3 - Núcleo de Estudos Hidrogeológicos e do Meio Ambiente, Instituto de Geociências/UfBA, Salvador (BA), Brasil. E-mail: lrogerio@ufba.br

4 - Department of Earth and Environmental Sciences, University of Texas at San Antonio, San Antonio, EUA. E-mail: alan.dutton@utsa.edu 
com conseqüente aumento do número de poços perfurados e rebaixamento do nível freático do aqǘfero ao longo dos últimos 20 anos (Silva 1973, Ramos 2005).

O aqüífero cártico da região de Irecê é um aqüífero livre associado às rochas carbonáticas neoproterozóicas do Grupo Una no estado da Bahia (Grupo Bambui em Minas Gerais), cuja morfologia foi esculpida por sucessivos ciclos de aplainamentos, resultando um platô dissecado com altitude média em torno de $800 \mathrm{~m}$. O aqǘf́ero apresenta superfície piezométrica acompanhando a topografia regional e fluxo subterrâneo em direção às calhas dos rios Verde, Jacaré e seus principais afluentes (Brito Neves 1967, Silva 1973, Bedmar et al. 1980).

A estimativa de valores e condições de recarga de aqüíferos cársticos têm sido um desafio para os hidrogeólogos de várias partes do mundo, especialmente em regiões onde há grande variação na distribuição espacial e temporal das precipitações (Carter \& Driscoll 2006). De modo geral, os valores da recarga e descarga têm sido monitorados a partir de uso de traçadores químicos, isotópicos, medidas físicas dos valores de descargas líquidas em nascentes, níveis freáticos (NF) a partir de monitoramento de poços e precipitações regionais (Leaney \& Herczeg 1995, Vandenschrick et al. 2002, Panagopoulos \& Lambrakis 2006). No caso do aqüífero cárstico da região de Irecê, estimativas da recarga regional a partir de dados isotópicos e medidas do nível freático, revelam valores médios entre 55 e $66 \mathrm{~mm} /$ ano (Bedmar et al. 1980, Guerra 1986, Ramos 2005, Beraldo 2005).

Este trabalho tem como objetivos apresentar os resultados do monitoramento da variação dos níveis freáticos do aqǘfero cárstico da região de Irecê e de medidas das precipitações regionais realizadas no período entre dezembro de 2002 e setembro de 2004. Os valores do nível freático obtidos são comparados com dados do monitoramento realizado durante o período de fevereiro de 1980 até abril de 1982 (Guerra 1986). Finalmente, como os resultados revelaram grande flutuação e rebaixamento no nível freático do aqüífero, são apresentadas sugestões para apoiar a implementação de critérios para gestão e uso sustentável das águas subterrâneas nessa região do semi-árido baiano.

\section{CONTEXTO GEOLÓGICO / HIDROGEOLÓGI-}

CO O aqǘfero cárstico da região de Irecê, localizado na região central do estado da Bahia, envolve as bacias hidrográficas dos rios Verde e Jacaré afluentes do rio São Francisco e na porção sul a bacia do rio Santo Antônio, afluente do rio Paraguaçu (Fig. 1). Nessa região, afloram unidades litoestratigráficas mesoproterozóicas, predominantemente de natureza siliciclástica, representadas da base para o topo, pelas Formações Tombador, Caboclo e Morro do Chapéu compondo o Grupo Chapada Diamantina e uma espessa seqüência carbonático-pelítica, neoproterozóica que compõe o Grupo Una (Supergrupo São Francisco). Finalmente, recobrindo as rochas pré-cambrianas, afloram coberturas detríticas tércio-quaternárias (Misi 1979, Souza et al. 1993, Souza et al. 2002).

A seqüência carbonático-pelítica do Grupo Una repousa discordantemente sobre os metassedimentos do Grupo Chapada Diamantina e é formada da base para o topo pelas Formações Bebedouro e Salitre. A Formação Bebedouro é constituída predominantemente por metassiltitos, metargilitos e metadiamictitos. Já a Formação Salitre, hospedeira do aqüífero cárstico, é constituída predominantemente por calcissiltitos, dolomitos e lamitos algais fracamente ondulados na base, gradando para calcilutitos, calcarenitos, dolarenitos e dololutitos oolíticos no topo (Souza et al. 1993).

Associado às rochas carbonáticas, são reconhecidos dois domínios estruturais, vinculados a duas fases de deformação compressionais brasilianas. O primeiro domínio envolve a porção sul do aqüífero (região de Iraquara/Mulungu do Morro) e os contatos leste e oeste com as rochas do Grupo Chapada Diamantina, onde as rochas carbonáticas apresentam estratificação planoparalela ondulada, amplos dobramentos com eixo N-S e lineamentos estruturais associados a falhas transcorrente de direção N-S (Fig. 1). Nesse contexto, desenvolveu-se um sistema cársticos cuja morfologia é caracterizada por elevada densidade de dolinas, normalmente com formato arredondado e grandes diâmetros (até 200 $\mathrm{m})$, maior espessura de solos e vales profundos. Já o segundo domínio estrutural, representado principalmente na porção central do aqüífero (região de Irecê/Lapão), é caracterizado pela presença de intensos cavalgamentos, com dobramentos e falhamentos de baixo ângulo associados e vergência para SSE. Nesse cenário, têm-se um sistema aqǘfero de natureza cárstico-fissural, pouco evoluído, dolinas com forma elíptica, e com pequeno diâmetro (entre $5-15 \mathrm{~m}$ ), alinhadas segundo os trends dos lineamentos estruturais E-W, além da presença de sumidouros e solos muito rasos (Guerra 1986, Bastos Leal et al. 2004, Ramos 2005) (Fig. 1).

Cadastramento de poços, realizado no ano de 2004, revelou a existência de cerca de 6.000 poços tubulares perfurados nesse aqüífero cárstico, e um incremento anual de cerca de aproximadamente 250 novos poços (Bastos Leal et al. 2004). Tratamento estatístico dos dados desses poços revelou que mais de $50 \%$ apresenta vazões menores que $7 \mathrm{~m}^{3} / \mathrm{h}$ e que apenas $8 \%$ deles possui vazões superiores a $25 \mathrm{~m}^{3} / \mathrm{h}$ (Luz et al. 2004). Os poços com maiores vazões estão em geral perfurados próximos aos grandes lineamentos estruturais regionais, nas zonas de descarga do aqüífero e em áreas próximas dos contatos com metassedimentos da Chapada Diamantina nas bordas leste e oeste do aqüífero.

De forma geral, o aqüífero apresenta nível freático $(\mathrm{NF})$ próximo à superfície, com profundidades menores que $15 \mathrm{~m}$, observados em mais de 50\% dos poços, enquanto níveis freáticos mais profundos $(>45 \mathrm{~m})$ são observados nas porções sul e sudeste (ex: região de Iraquara) (Luz et al. 2004, Silva 1973). Devido ao grande aumento de poços perfurados na região central do aqüífero, especialmente para atender às demandas das atividades agrícolas, têm-se observado rebaixamento do nível freático do aqüífero em cerca de $1,0 \mathrm{~m}$ por ano ao longo dos últimos 20 anos (Silva 1973, Ramos 2005). 

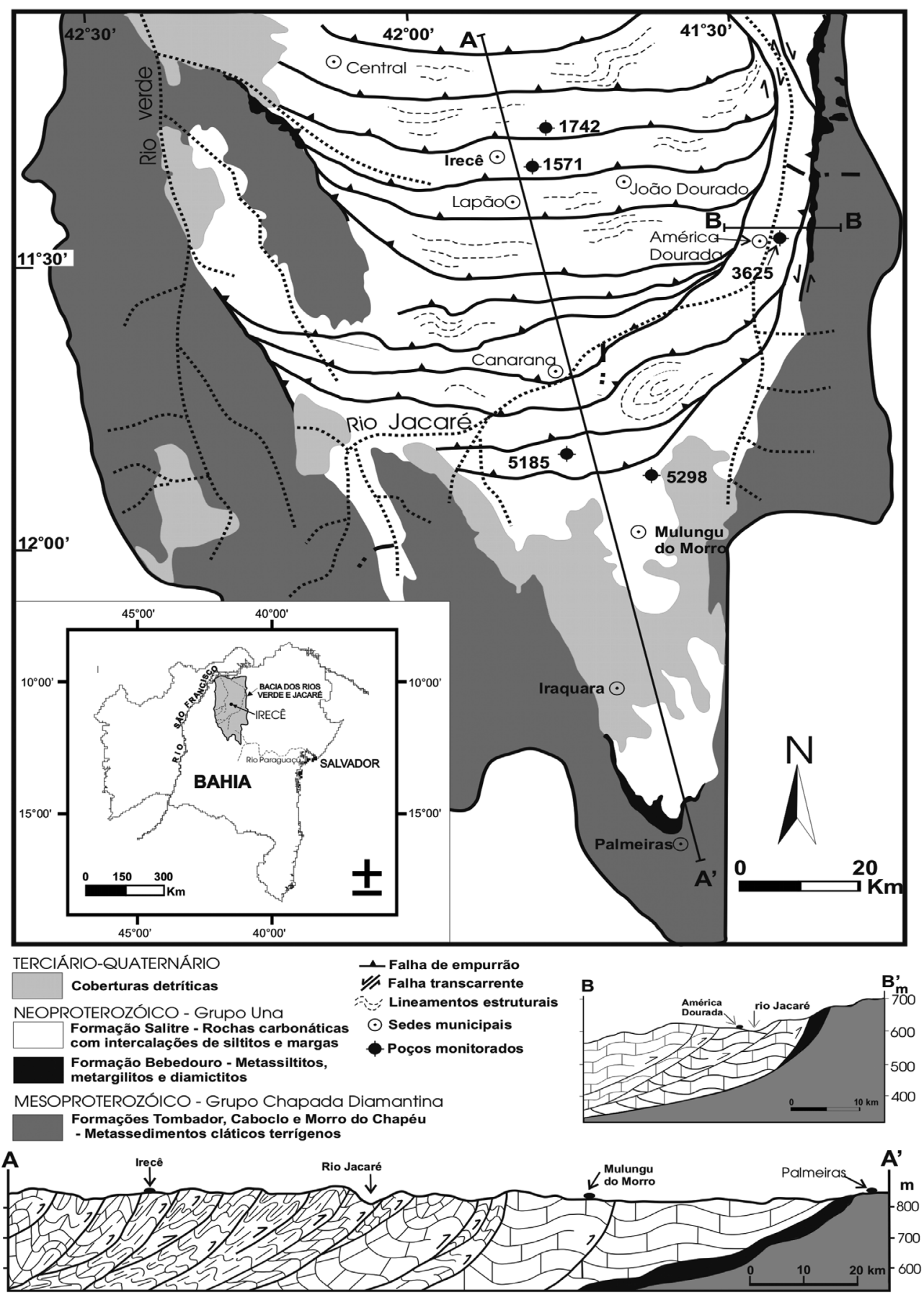

Figura 1 - Mapa geológico e localização dos poços monitorados no aqüifero cárstico da região de Irecê, Bahia.

CARACTERÍSTICAS CLIMATOLÓGICAS REGIONAIS A Região Nordeste do Brasil (NEB) é considerada uma região anômala do ponto de vista climático em relação às outras regiões tropicais dentro dessa faixa latitudinal. Esse espaço territorial apresenta uma diversificação climática complexa, apresentando grande variação espacial e temporal na precipitação pluviométrica (Fig. 2). Conforme registrado na estação meteorológica de Remanso (R), situada na porção central da NEB, o aqüífero cárstico da micro-região de Irecê está posicionado na área com clima tropical quente de seca de inverno e período seco de 5 a 8 meses, tendo o principal período chuvoso entre os meses de novembro e março.

Do ponto de vista local, o regime pluviométrico da região, observado em postos pluviométricos instalados na área estudada, referente ao período de 1961 a 1990, revela que os meses com maior índice pluviométrico coincidem com o padrão regional, com valores de precipitações médias mensais oscilando entre 80 e 120 mm (Fig. 3). A partir do mês de maio e prolongando-se até o mês de setembro os índices pluviométricos são reduzidos, com variação média mensal inferiores a 10 $\mathrm{mm}$. Registram-se precipitações médias anuais na re- 


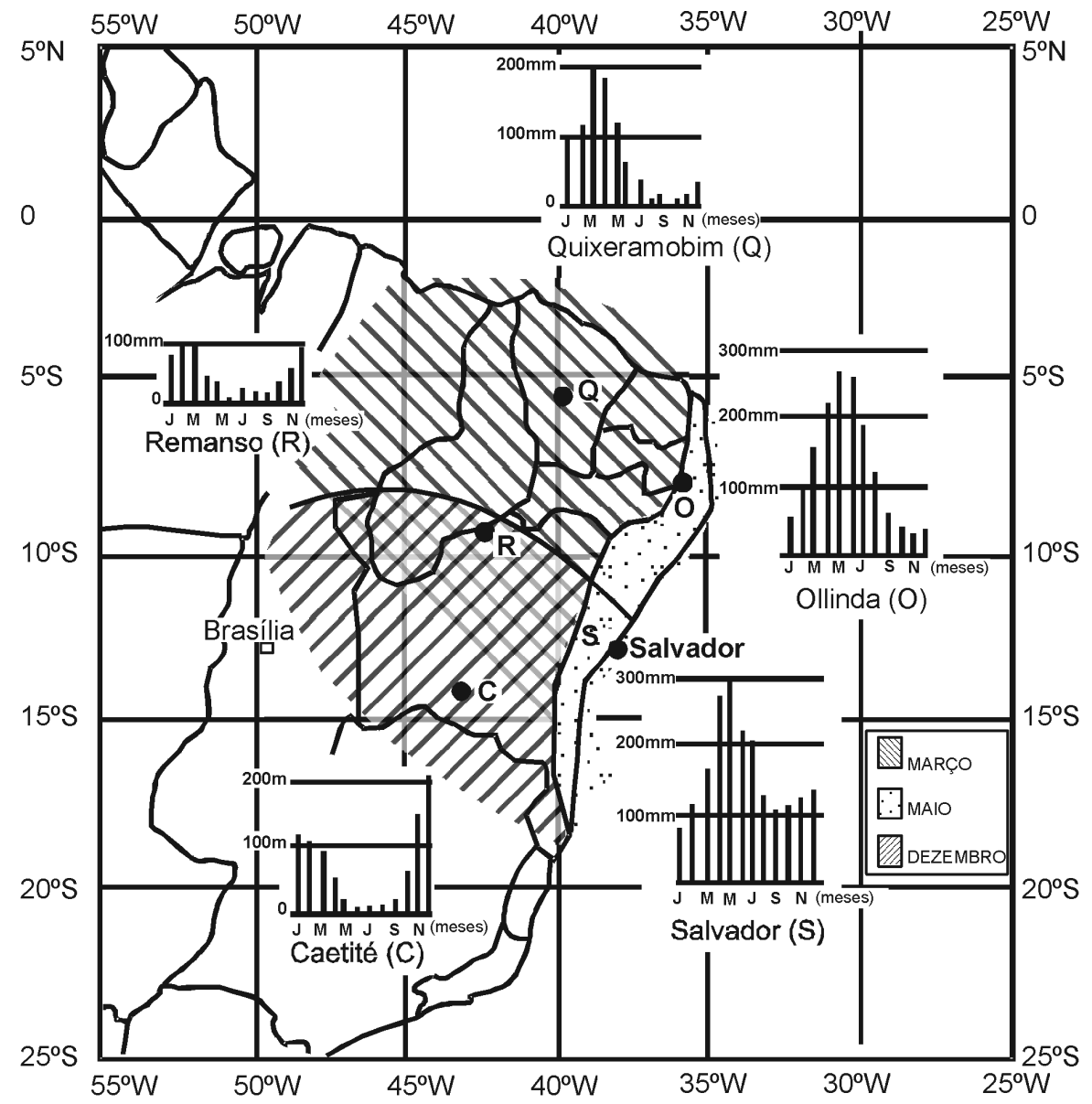

Figura 2 - Distribuição espacial e temporal da precipitação média mensal e histogramas da distribuição anual de precipitação medida em estações climatológicas na Região Nordeste do Brasil (NEB). Médias mensais do periodo entre 1931 e 1960 (Modificado de CPTEC-INPE 1996).

gião entre 500 e $600 \mathrm{~mm} / \mathrm{ano}$, enquanto a evaporação média registrada é de $2060 \mathrm{~mm} / \mathrm{ano}$ (INMET 1992).

RESULTADOS E DISCUSSÃO Durante o período de dezembro de 2002 a setembro de 2004, foram realizadas medidas do NF do aqüífero cárstico da região de Irecê em cinco poços tubulares desativados e medidas de precipitação. As medidas de NF foram realizadas a cada 15 dias no período das chuvas (outubro a março) e mensalmente no período de estiagem (abril a outubro). Os dados dos NF do aqüífero foram medidos com uso de medidores de nível elétricos, enquanto os valores de precipitação foram obtidos em estações pluviométricas instaladas nas sedes dos municípios próximos aos poços monitorados (Fig. 1). Durante os trabalhos de campo também foi realizado o levantamento de dados de posicionamento e altitude dos poços monitorados e estabelecidas comparações com os valores apresentados por Guerra (1986).

Os poços monitorados foram perfurados em diferentes posições do aqǘfero e apresentam profundidades entre 50 e $140 \mathrm{~m}$, entradas de água entre $10 \mathrm{e}$ $90 \mathrm{~m}$ e capacidades específicas variando entre 0,15 a $4,71 \mathrm{~m}^{3} / \mathrm{h} / \mathrm{m}$, revelando a característica heterogênea

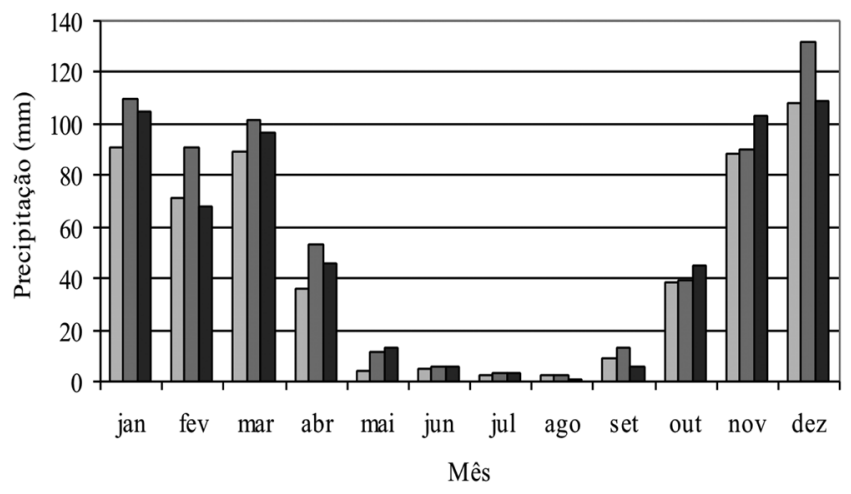

Figura 3 - Diagrama ilustrando os valores médios da precipitação mensal medida nos postos pluviométricos dos municípios de Cafarnaum, Canarana e Irecê. (Médias do periodo de 1961 a 1990, Fonte: INMET 1992, ANA 2004).

do comportamento hidráulico do aqüífero (Tab. 1). Os menores valores da capacidade específica são observados para os poços 1742 e 1542 localizados na região do município de Irecê, onde as rochas carbonáticas estão 
Tabela 1 - Dados dos poços monitorados no aqüifero cárstico da região de Irecê e valores da precipitação acumulada no periodo de recarga do aqüifero. Os valores de nivel estático (NE) e nível dinâmico (ND) foram obtidos durante os testes de bombeamento.

\begin{tabular}{|c|c|c|c|c|c|}
\hline № poço / $\operatorname{cota}(\mathrm{m})$ & $1742 / 829$ & $1571 / 776$ & $3625 / 664$ & $5298 / 837$ & $5185 / 846$ \\
\hline Coordenadas geográficas & $\begin{array}{l}41^{\circ} 45^{\prime} 32^{\prime \prime} \mathrm{W} \\
11^{\circ} 1625^{\prime \prime} \mathrm{S}\end{array}$ & $\begin{array}{l}41^{\circ} 47^{\prime} 22^{\prime \prime} \mathrm{W} \\
11^{\circ} 19^{\prime} 19^{\prime \prime} \mathrm{S}\end{array}$ & $\begin{array}{l}41^{\circ} 25^{\prime} 58^{\prime \prime} \mathrm{W} \\
11^{\circ} 26^{\prime} 55^{\prime \prime} \mathrm{S}\end{array}$ & $\begin{array}{l}41^{\circ} 44^{\prime} 09^{\prime \prime} \mathrm{W} \\
11^{\circ} 51^{\prime} 21^{\prime \prime} \mathrm{S}\end{array}$ & $\begin{array}{l}41^{\circ} 36^{\prime} 45^{\prime \prime} \mathrm{W} \\
11^{\circ} 53 \text { '27"S }\end{array}$ \\
\hline Profundidade (m) & 69 & 102 & 140 & 50 & 120 \\
\hline Profundidade das entradas de água (m) & 10,63 e 67 & 51 e 59 & 11,25 e 90 & 35 & 24 \\
\hline Vazão (Q) - (m³/h) & 11,6 & 6,3 & 144,0 & 11,3 & 5,8 \\
\hline Capacidade específica (Qs) - (m³/h/m) & 0,34 & 0,15 & 3,17 & 4,71 & 2,52 \\
\hline Precipitação acumulada no período dez/02-abr/03 (mm) & 432,4 & 432,4 & 325,0 & 328,5 & 495,9 \\
\hline Precipitação acumulada no período dez/03-abr/04 (mm) & 683,1 & 683,1 & 419,0 & 605,7 & 535,8 \\
\hline
\end{tabular}

intensamente dobradas e fraturadas e a carstificação é pouco desenvolvida. Por outro lado, os maiores valores de capacidade específica são observados nos poços monitorados na porção leste, revelando assim maior potencialidade para exploração das águas subterrâneas nesse segmento do aqüífero.

A variação do NF do aqüífero cárstico de Irecê em função do regime pluviométrico regional, no período de dezembro de 2002 a setembro de 2004, é apresentada nos diagramas da figura 4. Observa-se que o período de intensa precipitação regional e de recarga do aqǘfero, concentrou-se entre os meses de dezembro a abril em todas as estações pluviométricas, com valores acumulados médios de $402,8 \mathrm{~mm}$ e $585,3 \mathrm{~mm}$ para o primeiro e segundo ano de monitoramento, respectivamente (Tab. 1). As maiores variações no NF do aqüífero foram observadas nos poços 1742,1571 e 5185 , com destaque para o primeiro, onde o NF apresentou variação entre o período de chuva e de seca de $26,3 \mathrm{~m}$. Os eventos de precipitação regional registrados entre o final de março e início de abril de 2003 , cuja intensidade média foi de $89 \mathrm{~mm}$, não foram suficientes para promover a inversão da tendência de rebaixamento do NF do aqüífero a nível regional nesse período. Apenas na região dos poços 1571 e 1742 , observou-se elevação do nível d'água no aqüífero nesse período, onde o acumulado da precipitação alcançou valor de $186 \mathrm{~mm}$ (Fig. 4). Tal comportamento sugere que precipitações isoladas com valores inferiores a $100 \mathrm{~mm}$ não são suficientes para promover incrementos significativos na recarga do aqüífero.

De modo geral, no período de estiagem na região, entre os meses de maio a novembro, ocorre o rebaixamento do NF do aqüífero, sendo os maiores valores observados na porção central do aqüífero (poços 1742,1571 e 5185), enquanto na região dos poços 3625 e 5298 os rebaixamentos apresentaram valores em torno de $1,0 \mathrm{~m}$ em relação ao período de alta precipitação. Os rebaixamentos mais acentuados na porção central do aqüífero e na região a sul de Canarana (poço 5185) possivelmente estão condicionadas às descargas naturais do aqǘffero para os rios Verde e Jacaré e ao intenso bombeamento por meio de poços a que está submetido o aqüífero nessa região, uma vez que nesse segmento do aqüífero, concentra-se mais de $50 \%$ dos poços. Por outro lado, os menores valores do rebaixamento do NF observados nos poços da borda leste do aqǘf́rero, se relacionam com a maior carstificação, além de ser uma de zona de descarga natural, revelando ser uma das áreas de maior potencialidade para exploração de águas subterrâneas na região. Tal fato é também sugerido pelos maiores valores das capacidades específicas (média $=4,5 \mathrm{~m}^{3} / \mathrm{h} / \mathrm{m}$ ) dos poços perfurados nesse segmento do aqüífero.

A comparação das variações temporais dos níveis estáticos (NE) dos poços monitorados para os anos 1980-1982 e 2002-2004, revela que a recarga do aqüífero se dá por infiltração direta, durante o período de maior precipitação, entre os meses de dezembro e abril (Fig. 5). Esse comportamento foi também registrado por meio de resultados de análises isotópicas de $\delta^{18} \mathrm{O}$ e $\delta^{2} \mathrm{H}$ (Beraldo 2005). Por outro lado, constatou-se significativo rebaixamento do nível freático nos poços dos diferentes segmentos do aqüífero, com exceção da região do poço 3625 , onde foi observada a elevação do nível freático para um valor médio de $3,4 \mathrm{~m}$ e estável ao longo do ano hidrológico.

O amplo rebaixamento do aqǘf́ero, com valores superiores a $15 \mathrm{~m}$, observado nos poços 1742 e 5298, possivelmente está relacionado ao intenso bombeamento a que o mesmo vem sendo submetido nas últimas duas décadas (Figs. 5 e 6 ). Por outro lado, a subida do NF na região do poço 3625 , situado às margens do rio Jacaré, possivelmente representa a ampliação do fluxo subterrâneo para essa zona de descarga do aqüífero, devido a maior intensidade de precipitação no período 2003-2004 em comparação com o período de 1980 a 1982. 

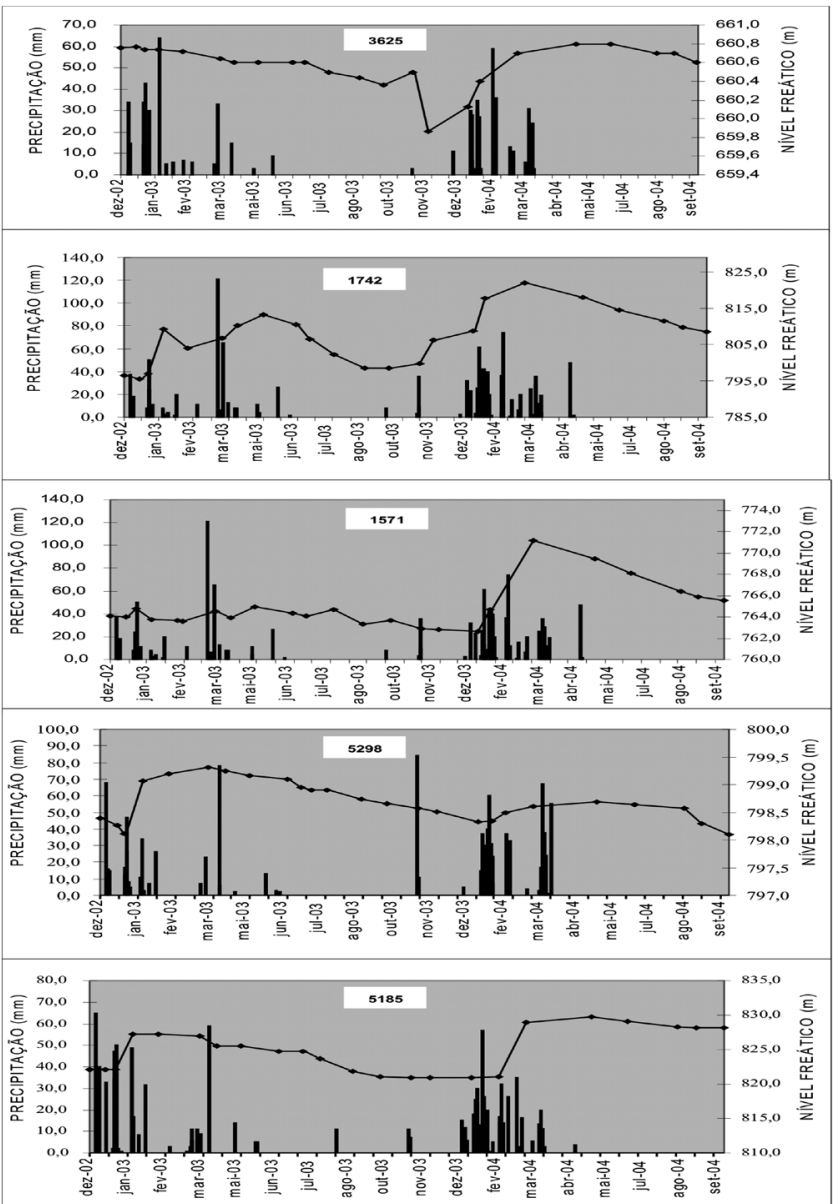

Figura 4 - Variação temporal da precipitação e do nivel freático (NF) do aqüifero cárstico da região de Irecê, Bahia.

CONCLUSÕES O monitoramento das variações da precipitação e do nível freático do aqüífero cárstico da região de Irecê, associado com a avaliação de informações disponíveis sobre as águas subterrâneas da região, permitiram reconhecer a variabilidade do comportamento da recarga do aqüífero, suas relações com os eventos de chuva na região e a heterogeneidade da estruturação hidrogeológica regional.

Apesar do número reduzido de poços de observação e a baixa densidade de postos pluviométricos, verificou-se que há variabilidade espacial e temporal da incidência de chuvas na região. Além disso, o menor volume anual da precipitação, associado ao aumento do escoamento superficial durante o período das chuvas, tem ocasionado a redução na recarga natural do aqǘ́fero. Por outro lado, devido aos altos valores da evaporação regional, chuvas isoladas com valores inferiores a $100 \mathrm{~mm}$ não são suficientes para promover a recuperação do NF do aqüífero.

A ampliação das áreas irrigadas nos últimos 20 anos, com uso intensivo das águas subterrâneas vem promovendo o rebaixamento do NF, indicando que o mesmo encontra-se sob regime de sobrexplotação e de forma não sustentável. Esse rebaixamento contínuo do
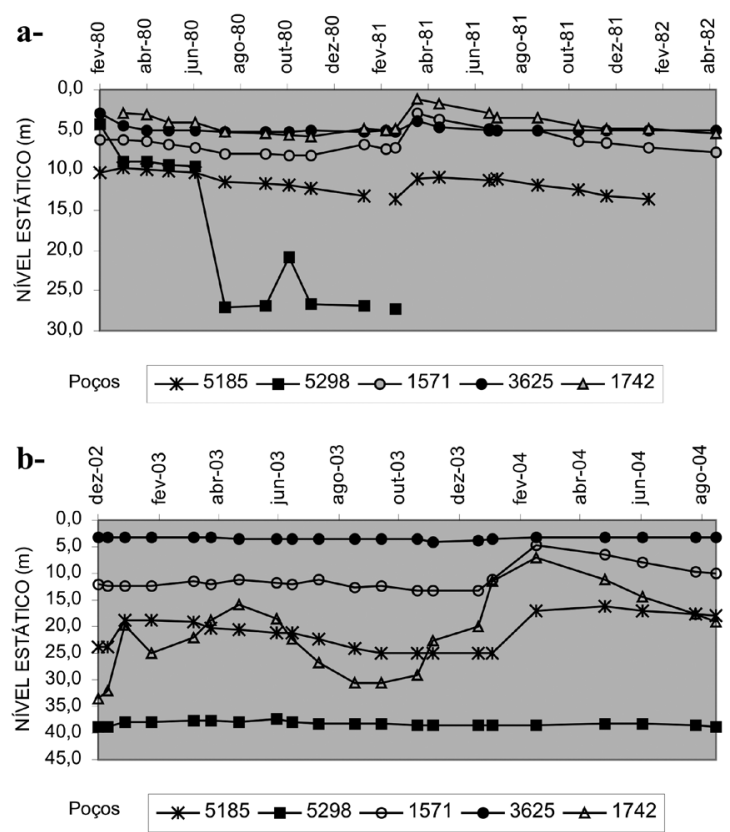

Figura 5 - Variação temporal do nível freático do aqüifero cárstico de Irecê, obtidos a partir do monitoramento em poços tubulares. a-Medidas realizadas entre fevereiro de 1980 e abril de 1982 (Guerra 1986), b- medidas realizadas entre dezembro de 2002 e setembro de 2004.

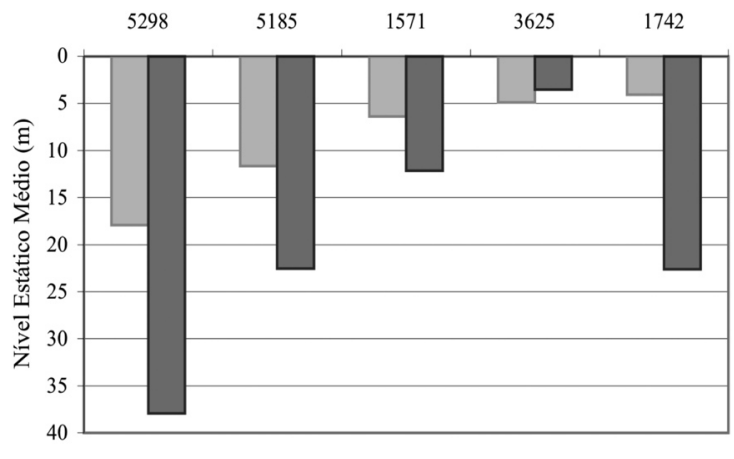

Figura 6 - Comparação da variação da profundidade dos niveis estáticos médios dos poços monitorados no período dos anos 19801982 e 2003-2004.

NF do aqüífero vem ocasionando a redução nas descargas naturais do aqüífero para os rios da região, sugerindo que a taxa de bombeamento atualmente praticada é superior à recarga anual. Esse processo de sobrexplotação está mais avançado na porção central do aqüífero entre os municípios de Irecê e Canarana, onde as atividades agrícolas estão mais concentradas e os rebaixamentos alcançam maiores valores.

Devido aos rebaixamentos do NF observados, há necessidade de adoção de medidas reguladoras no sentido de que uma nova condição de equilíbrio dinâ- 
mico seja estabelecida, onde a recarga seja igual ao somatório das descargas naturais e ao total de água que está se bombeando do aqüífero. Dessa forma, a realização de estudos hidrogeológicos de detalhe voltados para o estabelecimento de critérios normativos para a perfuração de novos poços e definição de vazões máximas de explotação são ações inadiáveis, de modo a garantir a gestão integrada das águas subterrâneas e superficiais e garantir condições para a manutenção das atividades agrícolas na região e a sustentabilidade ambiental.

Agradecimentos Os autores registram o agradecimento à Superintendência de Recursos Hídricos do Estado da Bahia - SRH/BA e ao Banco Interamericano de Reconstrução e Desenvolvimento (BIRD) pela concessão de recursos financeiros para o desenvolvimento deste trabalho. Também agradecem a CAPES pelo apoio financeiro no âmbito da Cooperação Internacional UFBA/CAPES/UTSA.

\section{Referências}

AGÊNCIA NACIONAL DE ÁGUAS 2004 (ANA). HidroWeb. Disponível em http://www.ana.gov.br. Acesso em junho de 2004.

Bastos Leal L.R.B. \& Silva H.P. 2004. Modelização da dinâmica hidrológica e instrumentos para a gestão do sistema aqüifero-rio das bacias hidrográficas dos rios Verde e Jacaré - região semi-árida do estado da Bahia. Relatório Técnico Final do Convênio 002/02, SRH/UFBA/FAPEX. v. $1,361 \mathrm{p}$.

Leal L.R.B., Lima O.A.L., Luz J. A.G., Ribeiro S.H.S. \& Silva A.B. 2004. Caracterização hidrogeológica da bacia do rio Salitre, região centro-norte do estado da Bahia. In: Encontro Brasileiro de Estudo do Carste, 1, Belo Horizonte, Anais, v.1, p. 60-60.

Bedmar A.P., Silva A.B., Jardim F.G. \& Oliveira L.B. 1980. Contribuição de diversas técnicas isotópicas no estudo do aqüífero cárstico da região central da Bahia (Irecê-Iraquara). Rev. Bras. Geoc., 10:104-116.

Beraldo V. 2005. Estudo isotópico $\left(\delta^{2} H \delta^{18} O\right)$ e hidroquímica das águas superficiais e subterrâneas na região de Irecê, Bahia: Contribuição ao entendimento do ciclo hidrológico regional. Dissertação de Mestrado, Instituto de Geociências, Universidade Federal da Bahia, 84 p.

Brito Neves B.B. 1967. Água subterrânea na região central da Bahia, condicionamento e demanda. Recife, CONESP, Relatório № 21, 32 p.

Carter J.M. \& Driscoll D.G. 2006. Estimating recharge using relations between precipitation and yield in a mountainous area with large variability in precipitation. J. Hydrol., 316:71-83.

CENTRO DE PESQUISAS E ESTUDOS CLIMÁTICOSINSTITUTO NACIONAL DE PESQUISAS ESPACIAIS (CPTEC-INPE). 1996. Boletim de Monitoramento e Análise Climática - Climanálise: Número Especial. Cachoeira Paulista, São Paulo, 223 p.

Guerra A.M. 1986. Processos de carstificação e hidrogeologia do grupo Bambuí na região de Irecê - Bahia. Tese de Doutorado, Instituto de Geoc., Univ. de São Paulo, 132 p.

INSTITUTO NACIONAL DE METEOROLOGIA (INMET) 1992. Normais Climatológicas. Brasília, 84 p.
Leaney F.W. \& Herczeg A.L. 1995. Regional recharge to a karst aquifer estimated from chemical and isotopic composition of diffuse and localised recharge, South Australia. J. Hydrol., 164:363-387.

Luz J.A., Bastos Leal L.R. \& Barreto F.S. 2004. Tratamento estatístico dos dados dos poços da região do Platô de Irecê-Bahia. In: ABAS, Cong. Bras. de Águas Subterrâneas, 13, Anais, p. 45-56.

Misi A. 1979. O Grupo Bambui no estado da Bahia. In: H.A.V. Inda (ed.) Geologia e recursos minerais do estado da Bahia: Textos básicos. Salvador, CPM, v.1, p. 119-154.

Panagopoulos G. \& Lambrakis N. 2006. The contribution of time series analysis to the study of the hydrodynamic characteristics of the karst systems: Application on two typical karst aquifers of Greece (Trifilia, Almyros Crete). J. Hydrol., 25:25-34.

Ramos S.O. 2005. Variações sazonais dos níveis hidrostáticos do aqüífero cárstico da região de Irecê, Bahia: Implicações para estimativa da recarga. Dissertação de Mestrado, Instituto de Geociências, Univ. Federal da Bahia, 137 p.

Silva A.B. 1973. Contribuição à hidrogeologia dos karsts da região da Bahia. Rev. Água Subterrânea, 3:11-16.

Souza S.L., Toledo L.A.A., Brito P.C.R., Fróes R.J.B. \& Silva R.W.S. 2002. Análise faciológica e metalogenética da bacia de Irecê, Bahia. Salvador, CBPM. Relatório Final, Companhia Baiana de Pesquisa Mineral, Textos, v. $1,110 \mathrm{p}$.

Souza S.L., Brito P.C.R. \& Silva R.W.S. 1993. Estratigrafia, sedimentologia e recursos minerais da Formação Salitre na bacia de Irecê, Bahia. Salvador, CBPM, Série Arquivos Abertos, Cia Baiana de Pesquisa Mineral, n.2, 36 p.

Vandenschrick G., van Wesemael B., Frot E., Pulido-Bosch A., Molina L., Stiévenard M. \& Souchez R. 2002. Using stable isotope analysis $\left(\delta \mathrm{D}-\delta^{18} \mathrm{O}\right)$ to characterize the regional hydrology of the Sierra de Gador, south east Spain. J. Hydrol., 265:43-55.

Manuscrito CSF-24

Submetido em 31 de maio de 2006 Aceito em 20 de agosto de 2007 